\title{
Mencermati Kepemimpianan Komprehensif dalam Asthabrata
}

\author{
Pardi Suratno
}

\author{
Balai Bahasa Provinsi DI Yogyakarta \\ pardis@gmail.com
}

\author{
Article History \\ received $1 / 9 / 2021$
}

revised $1 / 10 / 2021$

accepted 1/11/2021

\begin{abstract}
The concept of leadership is found in many Javanese old texts, such as Serat Asthabrata, Serat Wulangreh, and Serat Tripama. Among these old texts, the concept of leadership written in Asthabrata is regarded as the most popular one in the life of Javanese or Indonesian people. It is because the development of the leadership concept in Asthabrata was unique and interesting. Asthabrata's teachings were born in the Hinduism era and derived from Serat Ramayana. Following the Javanese society's belief that changed from Hinduism to Islam, the leadership concept of Asthabrata shifted. The Hinduism concept symbolized in Hindu Gods' roles turned symbolically into natural objects. It occurred because Islamic beliefs did not adhere to Hindu Gods; therefore, the concept was realized symbolically in natural objects, such as the sun, earth, moon, fire, ocean, star, wind, and cloud. One of the intriguing things to understand is that any of those objects provide no leadership. However, leadership is comprehensive - an ideal leader is the one who meets the characteristics of those objects, known as woluning atunggal (eight as unity). This article aims to describe the characteristics of comprehensive leadership in Asthabrata teachings as a reference to develop the ideal leadership concept in Indonesia.
\end{abstract}

Keywords: leadership, comprehensive, unity

\begin{abstract}
Abstrak
Konsepsi kepemimpinan banyak terdapat dalam naskah lama, termasuk naskah Jawa, seperti terdapat dalam Serat Asthabrata, Serat Wulangreh, dan Serat Tripama. Di antara naslah lama itu Konsepsi kepemimpinan dalam Asthabrata tergolong yang paling popular dalam kehidupan masyarakat Jawa atau Indonesia. Hal itu disebabkan oleh perjalanan konsepsi kepemimpinan dalam Asthabrata tergolong unik dan menarik. Ajaran Asthabrata lahir sejak zaman Hindu bersumber dari Serat Ramayana. Sejalan dengan perubahan keyakinan masyarakat Jawa yang bercorak Hindu yang beralih ke ajaran Islam, maka konsepsi kepemimpinan Asthabrata pun mengalami pergeseran dan konsepsi agama Hindu yang disimbolisasikan dalam peran tokoh dewa berubah menjadi simbolik benda-benda alam. Hal itu disebabkan oleh keyakinan dalam Islam yang tidak mengenal tokoh dewa sehingga diganti menjadi simbolik benda alam, seperti bumi, matahari, rembulan, api, samudra, bintang, angin, dan mendung. Satu hal yang menarik untuk dicermati adalah bahwa tidak ada kepemimpinan yang mampu diperankan oleh karakter satu benda alam tertentu. Akan tetapi, kepemimpinan itu bersifat kompehensif bahwa karakter pemimpin ideal adalah yang memenuhi kedelapan karakterk benda alam tersebut yang disebut woluning atunggal' delapan dalam kesatuan". Artikel ini akan mendeskripakan ciri kepemimpinan komprehensif dalam ajaran Asthabrata untuk diacukan dalam membangun konsepsi kepemimpinan Indonesia secara ideal.
\end{abstract}

Kata kunci: kepemimpinan, komprehensif, kesatuan

Social, Humanities, and Education Studies (SHEs): Conference Series https://jurnal.uns.ac.id/shes

p-ISSN 2620-9284

e-ISSN 2620-9292

This work is licensed under a Creative Commons Attribution-ShareAlike 4.0 International License. 


\section{PENDAHULUAN}

Sebagai konsepsi kepemiminan Jawa yang ideal, ajaran Asthabrata memiliki keunikan. Seorang pemimpin harus memiliki karakter yang mumpuni dan menguasai dua aspek dalam kehidupan, yakni harus mampu mengendalikan Jagad cilik dan jagad gedhe. Yang dimaksud jagad cilik adalah mikrokosmos, berupa menguasai diri sendiri agar ego positif selalu menjadi orientasi dalam kehidupannya. Sementara itu, dirinya juga harus mampu menguasai jagad gedhe yang disebut makrokosmos, yakni kehidupan sosial di luar dirinya sendiri sehingga mampu menjadi seornang yang berperilaku harmoni antara kepentingan individu dengan kepentingan sosial kemasyarakatan. Semua itu terdapat dalam wejangan kepemimpinan Asthabrata. Di sampaing itu, dalam kepemimpinan Jawa dikenal adanya karakter pemimpin yang berbudi bawa laksana 'bertingkap laku sesusi dengan apa yang diucapkan." dalam Konsepsi Jawa pemimpin harus mampu melindungi rakyat secara baik. Dalam konsep Jawa disebutkan karakater seorang pemimpian itu harus mampu menghapus kemiskinan rakyat dan membangun kemakmuran masyarakatnya. Kedua, Pemimpin harus mampu memberikan rasa aman dan nyaman kepada seluruh rakyatnya. Pendek kata, pemimpin harus mampu menyiapkan pangan bagi rakyatnya, menyediakan sandang bagi rakyatnya, dan memberikan rasa nyaman bagi rakyatnya serta memberikan layanan Kesehatan bagi rakyat yang disebutnya memberikan usada bagi orang yang sakit. Selain itu, seorang pemimpin Jawa dituntut mampu untuk memberikan jalan keluar bagi rakyat yang sedang menghadapi masalah. Maksudnya, pemimpin harus mampu mengatasi problema besar yang sedang terjadi pada masayarakat dan yang terakhir seorang pemimpin harus mampu memberi perlindungan atau pangayoman kepada masyarakat. Dalam konteks ini dapat dinyatakan sebagai sosok pemimpin yang ideal dalam kehidupan masa kini dan masa depan. Dirinya harus memerankan sebagai pencipta kesejahteraan, pemberi pencerahan atas semua problema kehidupan masyarakat dan menjadi pelindung atau pengayom bagi rakyat yang sedang mengalami problema hidup. Ajaran sosok ideal pemimpin Jawa adalah sebagaimana disebutkan oleh sang dalam pada adegan jejer kerajaan sbb.

Sang Prabu satunggaling ratu gung binatara sinuyutan kawula dhasih. Panjenengane suka paring sandhang marang wong kawudan, paring pangan marang kawulane kang nandhang kaluwen, paring toya marang sok sintena ingkang nembe kasatan, paring teken marang pawongan kang nandhang lelunyon, paring kudhung marang kawulane kang nembe kapanasan, paring payung marang kang lagi kodanan, paring suka marang sedaya kawula ingkang nembe nandhang priatos, paring usada mulya dhumateng sedaya ingkang nembe ginanjar sakit. Kajaba punika ugi kagungan raos tresna asih dhateng mengsah ingkang sampun anungkul. Pramila, mboten mokal lamun panjenengane sinuyudan dening para punggawa dalah kawula dasih.

\section{A. Konsepsi Kepemimpinan Astabarata}

Ajaran kepemimpinan Jawa terdapat dalam beberapa naskah Jawa seperti dalam Serat Asthabrata atau Serat Ramayana Kakawin, Serat Wulangreh, Serat Tripama, Serat Nayakawara, dan Serat Witaradya, dan sebagainya.

Seperti dinyatakan di atas ajaran kepemimpinan dalam Serat Asthabrata merupakan wejangan yang sangat popular. Salah satu popularitas tersebut disebabkan adanya dinamika wejangan kepemimpianan yang mengikuti alur berpikir masyarakat Jawa. Semula ajaran kepemimpinan itu mengambil simbolik peran para dewa sejalan dengan ajaran agama Hindu, yakni peran dewa seperti dinyatakan oleh Mudjija, 
(1967:16), yakni: (1) Dewa Endra, (2) Dewa Surya, (3) Dewa Bayu, (4) Dewa Kuwera, (5) Dewa Baruna (6) Dewa Yama, (7) Dewa Candra, dan (8) Dewa Brama. Sejalan dengan berubahnya keyakinan masyarakat Jawa menuju keyakinan Islam yang melarang mengambil teladan para dewa, terjadilah peralihan wejangan kepempimpinan itu dengan mengambil peran karakter simbolik benda-benda ala. Menurut Pradipta (1994), pergeseran itu diawali tatkala kelahiran ajaran Asthabrata dimuat di dalam Babad Sangkala. Kemudian, teladan watak kepemimpinan pada benda-benda alam itu semakin mengental dalam sosialisasi ajaran Asthabrata melalui pagelaran wayang purwa, seperti dalam cerita Makutharama.terjadi transformasi ajaran asthabrata pada masa Hindu menuju masa Islam. Dalam konteks ini, Pradipta (1994) menyatakan bahwa telah terjadi pergeseran orientasi dari alam kadewatan (keyakinan terhadap para dewa) kepada pemikiran yang berorientasi pada filsafat alam semesta. Watak kepemimpinan yang harus diteladani pun merujuk pada watak bendabenda alam. Sekalipun begitu, simbol benda-benda alam yang digunakan tidak jauh dari nama-nama dewa dalam Serat Rama Jarwa atau karya yang lebih dahulu dari kitab tersebut, yakni bahwa pemimpin perlu memiliki (1) watak bumi, (2) watak air atau samudra, (3) watak api, (4) watak angin, (5) watak surya atau matahari, (6) watak rembulan, (7) watak lintang atau bintang, dan (8) watak mendhung.

Adanya orientasi dari ajaran berbasis Hindu menuju ajaran berbasis Islam itu merupakan kecerdasan pujangga Jawa dalam mengemas ajaran kepemimpinan. Dengan cara seperti itu tidak terjadi konfliks dalam masyarakat. Pengarang melakukan Transformasi nilai dari nilai dalam ajaran agama Hindu dengan konsep kadewatan menjadi konsep Islam, yakni konsep benda alam. Ajaran Asthabrata disampaikan oleh Rama kepada Barata, adik tirinya yang ketika itu merasa tidak mampu memegang tampuk pimpinan sebagai raja. Dirinya mencari kakaknya Rama dan memintanya pulang dari pengembaraannya di tengah hutan dan selanjutnya menggantikan dirinya sebagai raja. Akan tetapi, Rama menolak untuk pulang dan menjadi raja. Sebaliknya, Rama memberikan nasihat berupa wejangan kepemimpinan asthabrata kepada Barata. Setelah menerima ajaran kepemimpinan dari Rama tersebut Barata merasa mendapat pencerahan sehingga dirinya pulang dan melanjutkan menjadi raja. Kedua, ajaran asthabrata diberikan oleh Rama kepada Wibisana. Wibisana adalah adik kandung Raja Dasamuka yang membelot mengikuti pasukan Rama. Hal itu disebabkan karena Wibisana tidak sependapat dengan tindakan Dasamuka yang menculik Dewi Sinta, istri Rama. Ketiga, ajaran asthabrata disampaikan oleh Raja Kresna yang berperan sebagai Begawan Kesawasidhi kepada Arjuna dalam lakon wayang Makutharama.

\section{B. Deskripsi ajaran Kepemimpinan dalam Asthabrata}

Di atas dijelaskan terjadi transformasi wejangan asthabrata dari konsepsi Hindu menuju konsepsi Islam. Transformasi itu terjadi dari Dewa Pertiwi menjadi bumi; dari Dewa Baruna menjadi samudra;dari Dewa Agni menjadi api; dari Dewa Bayu menjadi angin; dari Dewa Surya menjadi matahari; dari Dewa Candra menjadi rembulan; dari Dewa Kartika menjadi bintang; dari Dewa Waruna menjadi awan. Dalam konsepsi itu tidak bersifat mono consept atau konsepsi tunggal melainkan Unity consept atau konsepsi secara utuh. Maksunya karakter pemimpian tidak sempurna dalam karakter satu tokoh atau satu benda alam, melainkan sebagai kumpulan dari konsepsi kepemimpinan. Oleh sebab itu, dalam menjelaskan konsepsi itu kita mulai dari kerangka berpikir induktif atau satu satu untuk menarik simpulan yang menyeluruh atau deduktif.

Pemimpin berwatak bumi memiliki karakter yang Sentosa, perkasa, kuat, dan kokoh. Di samping, itu bumi juga sebagai simbol suci dan tulus. Sentosa atau kokoh merupakan watak bumi yang tidak goyah diinjak atau ditempati oleh apapun juga. Tulus atau suci maksudnya bumi memiliki sifat rela diinjak oleh semua orang, baik 
orang baik maupun orang buruk, bahkan penjahat sekalipun. Jadi, bumi memiliki sifat yang sangat tulus dalam melayani semua orang. Bumi menggambarkan watak pemimpin yang memiliki pribadi sentosa hati dan pendiriannya. Tidak mudah terpengaruh bujukan dan rayuan dari pihak manapun. Suci pikirannya sehingga ucapan dan perilakunya bersifat riil sehingga mudah diaplikasikannya. Dampak dari sifat bumi adalah ketulusan perilaku bumi menyebabkan rakyat menyayanginya, rakyat semakin setia sehingga semakin wibawalah dirinya dalam memegang tampuk pimpinan.

Pemimpin berwatak Dewa Baruna atau Samudra mengedepankan sifat luas pikirannya yang tanpa batas, mampu menampung persoalan negara laksana lautan atau Samudra yang riil menampung kotoran yang diangkut oleh sungai-sungai besar, pemimpin yang luas wawasannya luas budi dan rohaninya. Pemimpin berwatak Samudra mampu menerima atau menghadapi segala persoalan negara. Dengan demikian, pemimpin berwatak Samudra akan mampu mewujudkan situasi yang damai, tenang, rukun dan bersatu seluruh elemen negara, mampu menghentikan perselisihan yang timbul sehingga rakyat semakin patuh dan tunduk kepadanya.

Pemimpin berwatak Dewa Agni atau berisfat api memiliki karaketer mampu menghukum semua pihak yang bermasalah tanpa pandang bulu. Laksana api yang membakar semua benda yang ada. Tidak pilih kasih. Berikutnya api bermanfaat bagi kehidupan sehingga pemimpin berwatak api adalah pemimpin yang mampu menerapkan hukum tidak pilih kasih yang disebabkan pihak tertentu memiliki hubungan keluarga, persahabatan, dan lawan secara adil dan terukur. Jadi, pemimpin berwatak api diharapkan mampu membasmi kejahatan demi menciptakan keselamatan, kebahagiaan, dan kesjeahteraan rakyat lahir dan batin. Jadi, aktivitas api diabdikan bagi upaya-upaya menciptakan kemaslahatan rakyat. Dampak positifnya adalah mampu menciptakan negara tata tentrem akibatnya negara tumbuh menjadi negara yang kuat yang lahir dari keadilan yang diciptakan oleh pemimpin berwatak api.

Pemimpian diharapkan memiliki wstak angin yang merupakan transformasi dari Dewa Bayu dalam ajaran Hindu. Angin berwatak mampu meneliti persoalan negara ke segala penjuru tempat dan kehadirannya tidka dirasakan atau tidak diketahui sehingga mampu mendapatkan data dari semua persoalan bangsa yang ada. Pemimpin berwatak angin adalah pemimpin yang berkarakter mampu menjalankan pemerataan kepada semua wilayah atau rakyatnya. Pemimpin harus mampu mencari informasi ke segala penjuru mengemban tugas intelejen untuk mencsri masukan bahan pemecahan masalah dengan data yang akurat dan valid atau benar. Itu mampu diperankan oleh angin yang memiliki kemampuan masuk ke setiap lini kehidupan. Dampak positifnya adalah pemimpin berwatak angin akan mampu membuat pemerataan kesejahteraan negara sehingga mampu menjadikan negara menjadi besar bahkan sebagai negara agung.

Pemimpin berwatak matahari ditransfromasikan dari pemimpin berwatak Dewa Surya. Surya artinya matahari. Pemimpin berwatak matahari memiliki karekter menyenangakan seluruh rakyat seperti sifat sinar matahari yang bermanfaat bagi seluruh makhluk. Sinar yang bermanfaat bagi seluruh makhluk ini diibaratkan menyenangkangkan seluruh rakyat. Pemimpin berkarakter matahari akan menerapkan peraturan yang menjadi surmber pneghidupan kemuliaan seluruh rakyat Dampak positifnya adalah seluruh rakyat menjadi tarang hatinya serta membawa kecukupan dalam hidupnya. Seluruh rakyat bersungguh sungguh bekerja sehingga mengakibatkan negara sejahtera.

Pemimpian berkarakter rembulan merupakan transformsi dari karakter Dewa Candra. Wataknya seinar rembulan itu sejuk dan menerangi semua makhluk. Menerangi semua orang baik yang jahat maupun yang mulia. Karena mengeluarkan sinar yang sejuk sehingga menyenangkan semua orang. Rembulan disebut dewi malam artinya dewi yang memberikan kebahagiaan kepada sang ksatria. Pemimpin 
berwatak rembulan harus mampu memberi terang jalan kebenaran sewaktu negara mengalami persoalan atau negara dalam keadaan bermasalah. Pemimpin harus mampu membuat tenang hati seluruh negara. Dampak positifnya seluruh rakyat akan patuh membantu negara karena hatinya sudah dibuat tenang dan senang oleh pemimpin. Akibatnya negara menjadi hidup makmur dan damai.

Pemimpin berwatak bintang sebagai transformasi dari pemimpin berwatak Dewa Kartika. Fungi bintang adalah untuk memperindah langit. Lintang juga sebagai petunjuk arah bagi para nelayan di lautan dan petani dalam bercocok tanam. Pemimpin berwatak bintang menjadi pusat keindahan negara. Pemimpin menjadi sumber kesusilaan dan budaya tinggi atau adiluhung. Pemimpin menjadi teladan atau arah dan panutan bagi rakyat. Dampak positif dari karakter pemimpin berwatak bintang adalah meningkatkan keutamaan dan kemasyuran negara dan bangsa.

Pemimpin berkarakter mendung sebagai transformasi dari pemimpin beerwatak Dewa Waruna. Karakter mendung adalah menakutkan. Mendung akhirnya menjadi hujan yang memberi kesuburan bagi bumi.ini mengandung simbolik bahwa pemimpin itu harus memiliki wibawa atau menakutkan. Akan tetapi, ending-nya rakyat menjadi bahagia seperti turunnya hujan yang meneyuburkan bumi. Pemimpin harus berwibawa membuat rakyat menghormatinya, tetapi akhirnya atau anding-nya raja atau pemimpin mampu memberikan kemuliaan dan ketenteraman rakyat. Rakyat menghormati peraturan negara atau juga larangan negara. Dampaknya menyebabkan tegaknya peratauran negara.

\section{Konsepsi Kesatuan}

Kedelapan konsepsi kepemimpinan dalam asthabrata tersbut tidak berdiri sendiri. Akan tetapi, dinyatakan dalam teks asthabrata sebagai woluning atunggal artinya delapan dalam kesatuan. Pemimpian yang bagus adalah pemimpin yang berwatak Dewa Pertiwi, Dewa Baruna, Dewa Agni, Dewa Bayu, Dewa Surya, Dewa Candra, Dewa Kartika, Dewa Waruna atau kesatuan dari watak pemimpin sebagai watak bumi, samudra, api, angin, matahari, rembulan, bintang, dan angin.

Dengan demikian, pada intinya secara ideal seorang pemimpin mampu memerankan diri sebagai delapan watak Dewa atau benda alam tersebut. Itu konsepsi ideal. Jika tidak memungkinkan dapat juga mencapai semi ideal misalnya memenuhi karakter dari tujuh atau enam karekater pemimpin dalam asthabrata. Namun, tidak dapat karakter lain diabaikan sama sekali. Jika itu terjadi akan meneimbulkan ketimpangan dalam mengendalikan roda pemerintahan.

\section{Astahbarata sebagai Konsep Pemimpin Masa Depan}

Konsepsi pemimpin asthabrata dapat diacukan bagi upaya mewujudkan karekter pemimpin masa depan. Dengan merangkum watak baik dari delapan karekater pemimpin itu bisa menjadi idelaisasi pemimpin masa depan. Pemimpin masa depan adalah pemimpin yang kuat yang cerdas, yang mampu mengantarkan masyarakat hidup tenang nyaman dan sejahtera lahir dan bati, seperti pemimpin yang memiliki watak bumi rembulan, lintang, dan mendung. Peminpin masa depan bukan hanya mewakili satu karakter saja misalnya kuat, atau tegas semata. Akan tetapi, tegas dan penuh wibawa atau penampilan agak menakutkan namun secara fsikis mampu membangun masyarakat hidup bahagia. Bukan pemimpin yang mementingkan pencitraan agar dilihaat oleh rakyat baik semata. Namun, pemimpin yang realitis dan objektif seperti kepolosan watak bumi.dan menyenangkan hati seluruh rakyat laksana rembulan yang disebut dewi malam.

Pemimpin tidak boleh mengabaikan salah satu dari watak benda alam. Jika diabaikan dapat menimbulkan ketimpangan dalam pemerintahan. Ketimpangan dalam satu hal akan berdampak pada kurang mampunya seseorang mengemban Amanah negara. Jadi, Konsepsi wolu-woluning atunggal menjadi konsep ideal yang membawa 
dampak positif terhadap negara. Konsepsi kepemimpin dalam asthabrata ini semakin sempurna ajika dipadukan dengan watak kepemimpinan dan naskah Jawa yang lain misalnya Serat Wulangrehkarya Pakubuwana IV. Setidaknya ada tiga jenis karakter yang dapat dikembangkan pada masa kini dan masa depan. Pertama, adalah pemimpin negara harus tahu halal dan haram sebuah persoalan. Mengetahui halal dan haram berarti mengetahui baik dan buruk sebuah persoalan setelah dirinya mengambil keputusan penting. Kedua, pemimpin perlu memiliki watak sederhana yakni sederhana dalam berkata dan bersikap. Kesederhanaan itu merupakan manifestasi ketulusan pengebadiannya kepada rakyat dan negara. Ketiga, pemimpin harus memiliki jiwa loyalitas dan pengabdian. Pemimpin harus loyal sebagai bentuk pengabdiannya harus rela berkorban demi bangsa dan negara. Jiwa dan raganya diabdikan untuk kepentingan banga jika diperlukan tidak mengenal lelah dalam pengabdian. Keempat, pemimpin harus tidak bermental pedagang. Artinya, pemimpin jangan merasa dirinya mberutang atau meminjamkan kebaikan kepada negara. Kalau memakai konsep meminjamkan atau mengutangkan kepada negara pastilah suatu saat dirinya berharap utang atau pinjaman itu harus dibayarnya. Tidak boleh berwatak pedagang yang berpikir untung rugisecara ekonomi dalam menjalankan tugas negara.

\section{SIMPULAN}

Dalam acara Asthabrata pemimpin harus memiliki karakter yang mumpuni dan menguasai dua aspek dalam kehidupan, yakni jagad cilik dan jagad gedhe. Yang dimaksud jagad cilik adalah mikrokosmos, berupa menguasai diri sendiri agar ego positif selalu menjadi orientasi dalam kehidupannya. Sementara itu, dirinya juga harus mampu menguasai jagad gedhe yang disebut makrokosmos, yakni kehidupan sosial di luar dirinya sendiri sehingga mampu menjadi seornang yang berperilaku harmoni antara kepentingan individu dengan kepentingan sosial kemasyarakatan. Asthabrata mengajarkan bahwa pemimpian yang bagus adalah pemimpin yang berwatak Dewa Pertiwi, Dewa Baruna, Dewa Agni, Dewa Bayu, Dewa Surya, Dewa Candra, Dewa Kartika, Dewa Waruna. Merujuk Asthabrata sebagai konsep pemimpin masa depan, artinya pemimpin masa depan haruslah seseorang yang kuat yang cerdas, yang mampu mengantarkan masyarakat hidup tenang nyaman dan sejahtera lahir dan batin, seperti pemimpin yang memiliki watak bumi rembulan, lintang, dan mendung. Peminpin masa depan bukan hanya mewakili satu karakter saja akan tetapi, tegas dan penuh wibawa atau penampilan agak menakutkan namun secara fsikis mampu membangun masyarakat hidup bahagia.

\section{DAFTAR PUSTAKA}

Adi Triyono. 1989. "Memahami Ajaran Keprajuritan dalam Tripama dan Wirawiyata" dalam Widyaparwa Nomor 33. Yogyakarta: Balai Peneli $\neg$ ti $\neg$ an Bahasa.

Bratakesawa. 1950. Andharan Kalatidha Ranggawarsita. Surabaya: Pustaka $\mathrm{Na} \neg$ sio $\neg$ nal.

Budya Pardipta. 1997. Pengaruh Ramayana ke dalam Filsafat Hidup Jawa dan Tantangannya.

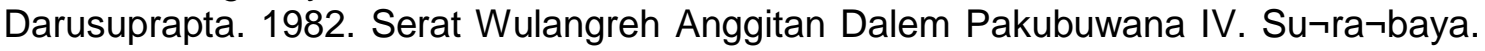
Citra Jaya.

Hariwijaya. 2003. Hikmah-Hikmah Hidup Serat Jayabaya. Nirwana.

Kamadjaja. 1969. Zaman Edan. Yogyakarta: UP Indonesia.

1985. Lima Karya Pujangga Ranggawarsita. Jakarta: Balai Pus $\neg$ taka.

Ki Sumidi Adisasmita. 1975. "Sekitar Ki Pujangga Ranggawarsita." Yogya $\neg$ karta: Yayasan Sasrakartana.

Hardjasarkara. 1964. Tripama-Wirawiyata. Soerakarta: Keluarga Soe - barna.

Mudjija. 1967. "Pandangan tentang Serat Asthabrata serta Nilainya di dalam Pendidikan Bahasa dan Kesusastraan". Yogyakarta: IKIP Yogyakarta. 
Pakubuwana IV. 1977. Serat Wulangreh. Sala. Indah Jaya.

Pardi Suratno. 2004. Reformasi Dalam Pandangan Penyair Kalimanatan Timur. Sama $\neg$ rinda: Kantor Bahasa Provinsi Kalimantan Timur.

2003. Kerinduan terhadap Budaya Tradisi. Yogyakarta: Lem $\neg$ baga Pelestarian dan Pengembangan Budaya Jawa. 2003. Sosok Pemimpin dalam Konsep Jawa. Yogyakarta: Yayasan Dharma Bhakti Budaya Nusantara dan Lembaga Pelestarian dan Pengembangan Budaya Jawa. . 2001. Reformasi Dalam Pandangan Pengarang Jawa dalam Widyaparwa. Yogyakarta: Balai Bahasa Yogyakarta. dan Henniy Astiyanto. 2005. Gusti Ora Sare: 65 Nilai Kearifan Budaya Jawa. Yogyakarta: Adi Wacana. Cetakan ke-2.

Padmawidagda, Raden B. dan Raden Ngabei Hanggapradata. 1933. Serat Kala $\neg$ tidha. Surakarta: Persatuan.

Tjitraprakoso. Raden Ngabei t.t. Nyuraos Serat Tripama-Wirawiyata. Sala: Keᄀluarga Soebarno.

Prawiraatmadja. S. 1958. Ngungak Isining Serat Asthabrata. Jogjakarta: Tjabang Bagian Bahasa Djawatan Kebudajaan Kementrian P.P. dan K.

Serat Wedatama: Nyuraos saha Gancaripun. Sala: Indah Jaya.

Soetarno. 1960. Kidungan saha Djakalodhang-Sabdadjati. Surakarta: Ke Soebarno.

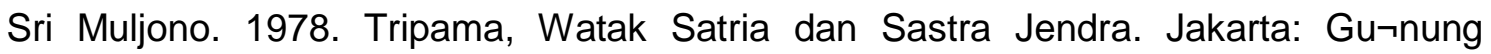
Agung.

Poerwadarmina, W.J.S.. 1939. Baoesastra Djawa. Batavia: Bale Poestaka 